\title{
Difference in ocular surface temperature by infrared thermography in phakic and pseudophakic patients
}

This article was published in the following Dove Press journal:

Clinical Ophthalmology

9 March 2015

Number of times this article has been viewed

\author{
Matthew Sniegowski \\ Michael Erlanger \\ Raul Velez-Montoya \\ Jeffrey L Olson \\ Ophthalmology Department, \\ University of Colorado School of \\ Medicine, Rocky Mountain Lions Eye \\ Institute, Aurora, CO, USA
}

Purpose: To assess the change in ocular surface temperature between healthy phakic and pseudophakic patients.

Methods: We included patients with no history of ocular disease other than cataract. Patients were divided into three groups: clear lens, cataract, and pseudophakic. All patients had two ocular surface digital thermal scans. An average of five surface points was used as the mean ocular surface temperature. Results were analyzed with a one-way analysis of variance and a Tukey's least significance difference test. The patients were further divided into phakic and pseudophakic groups. Correlation coefficients between several variables were done in order to assess dependencies.

Results: Fifty-six eyes ( 28 cataracts, 12 clear lenses, 16 pseudophakic) were enrolled. The mean ocular surface temperature in the cataract group was $34.14^{\circ} \mathrm{C} \pm 1.51^{\circ} \mathrm{C}$; clear lens: $34.43^{\circ} \mathrm{C} \pm 2.27^{\circ} \mathrm{C}$; and pseudophakic: $34.97^{\circ} \mathrm{C} \pm 1.57^{\circ} \mathrm{C}$. There were no statistical differences among the study groups $(P=0.3)$. There was a nonsignificant negative correlation trend between age and surface temperature in the phakic group. The trend inverted in the pseudophakic group but without statistical significance.

Conclusion: Although cataract extraction and intraocular lens implantation seem to induce a mild increase in ocular surface temperature, the effect is not clear and not significant.

Keywords: digital thermal scans, intraocular lens implantation, cataract extraction

\section{Introduction}

Human metabolic processes generate energy in the form of heat. ${ }^{1}$ In the human body, that energy must be dissipated through the body surface. ${ }^{1}$ Thermoregulation is a balance between heat generation and dissipation where vascular changes and sweat evaporation play important roles in keeping the body temperature stable. ${ }^{1-3}$ Each part of the body has its own temperature range based on the environment, location, vascularity, and metabolic activity. However, certain conditions like inflammation (local erythema and swelling) can cause local increases in temperature, ${ }^{4}$ due to an increase in vascular and metabolic activity, surface temperature of any specific body part can be determined by sensing the transmission of infrared radiation. ${ }^{4}$ According to Planck's blackbody radiation law, all bodies with a temperature above absolute zero $\left(-273^{\circ} \mathrm{C}\right)$ radiate certain electromagnetic waves that correspond to their specific temperature, and its total quantity can be calculated by the Stefan-Boltzmann equation. ${ }^{14,5}$ In 1915, observations made by Hartridge et al concluded that there was no difference between the infrared radiation of eye tissue and those of water. ${ }^{5}$ This means that at radiation levels above $3 \mu \mathrm{m}$ wavelength, the human eye behaves as a blackbody radiator and,
Ophthalmology Department, University of Colorado School of Medicine, Rocky Mountain Lions Eye Institute, 1675 Aurora Court, Aurora, CO 80045, USA Tel +l 7208482500

Fax +17208485014

Email jeffrey.olson@ucdenver.edu 
with an ocular temperature of about $32^{\circ} \mathrm{C}$, each part must emit a spectrum of radiation between $1 \mu \mathrm{m}$ and $30 \mu \mathrm{m}$ (infrared) in which the entire transmission of one tissue will be absorbed by tissue immediately anterior to it and its contribution to the final ocular surface temperature would be so small that it can be ignored. ${ }^{1,5,6}$ However, more than a hundred years later and by using modern thermographic acquisition devices, investigators have demonstrated that patients with conditions that increase the intraocular metabolic and vascular activity of the eye (iridocyclitis) showed a "hot ring" transmitted into the cornea surface above the ciliary body. ${ }^{7}$ Furthermore, the ocular surface temperature in those cases was $2.2^{\circ} \mathrm{C}$ higher than the normal controls, and there was a temperature difference of up to $3^{\circ} \mathrm{C}$ between the eyes that had undergone cataract surgery and the nonoperated eye. ${ }^{7,8}$ Conversely, other studies have failed to show or have shown little correlation between choroidal abnormalities and ocular surface temperature changes and have postulated that, in concordance with the observations made by Hartridge, any metabolic heat produced by the posterior eye will be dissipated by the highly vascularized retina and any thermal gradient will be minimal and unlikely to influence the final temperature of ocular surface. ${ }^{6,8,9}$

Digital thermography is a noninvasive, noncontact imaging procedure able to record wavelengths in the infrared spectrum instantaneously, resulting in an accurate representation of the objects temperature in real time., ${ }^{40}$ This technique has been used successfully in several medical fields; it has been used to control bypass circulation during cardiac surgery, ${ }^{7}$ in breast cancer detection, ${ }^{11}$ peripheral vascular diseases differential, ${ }^{3}$ diabetes neuropathy evaluation, ${ }^{12}$ detection of angiogenesis in tumors, ${ }^{13}$ detection of rheumatic diseases, ${ }^{14}$ and dental applications, among others. ${ }^{1,15}$ In ophthalmology, its uses include diagnostic imaging of dry eye ${ }^{4,12}$ retinal vein occlusion, and diabetic retinopathy evaluation, and the investigation of several pathological states of the adnexa and the response to steroid treatment in thyroid eye disease. ${ }^{12,16,17}$ Some studies have found a correlation between ocular surface temperature and choroidal flow as well as an inverse correlation with intraocular pressure in animal models. ${ }^{16,18}$

Since the understanding of the mechanism of thermal behavior in the human eye is central for the optimization of the use of digital thermography as a diagnostic and prognostic factor and since the role of posterior intraocular structures in ocular surface temperature is somewhat controversial, the purpose of this study was to assess the changes in ocular surface temperature between healthy phakic and pseudophakic patients, while controlling for several potential confounding factors, in order to optimize the reliability of the test.

\section{Methods}

The study was conducted at the Rocky Mountain Lions Eye Institute, Anschutz Medical campus. The study was reviewed and approved by the Colorado Multiple Institutional Review Board. All patients signed an informed consent, and the study strictly followed the tenets of the Declaration of Helsinki.

We included consecutive healthy patients (phakic and pseudophakic) from the cornea clinic, with no history of ocular diseases other than age-related cataracts (ARCs). All pseudophakic patients had at least 3 weeks without using topical drugs and at least 1 month or more since their phacoemulsification surgery. We excluded patients with clinically diagnosed diabetes or other systemic diseases like cancer, cardiovascular or autoimmune diseases, glaucoma, high myopia or hypermetropia, inflammatory eye diseases, dry eye or patients in whom surgical complications or loss of vitreous were reported. We also excluded patients who were currently using topical drugs for any cause. Dry eye assessment and diagnosis were done following the recommendations and guidelines of the International Task Force Delphi Panel and the International Dry Eye Workshop. ${ }^{19,20}$

The patients were divided into three main groups: phakic with clear lens, phakic with cataract, and pseudophakic with successful posterior chamber intraocular lens (PCIOL) implantation. Only ARCs were included regardless of their individual stratification.

\section{Digital thermal image}

All patients were acclimated to the clinical environment for at least 15 minutes. The room temperature was specifically set and controlled at all times at $22^{\circ} \mathrm{C}\left(\approx 72^{\circ} \mathrm{F}\right)$, humidity was maintained at $42.0 \%$, and the average indoor illumination was maintained at 300 lux. Two thermal scans of each subjects orbits and bilateral ocular surfaces were taken by using a FLIR ${ }^{\circledR}$ T420 Thermal digital camera with thermal digital enhancement (FLIR Systems Inc., Boston, MA, USA), with an accuracy of $\pm 2 \%$; thermal sensitivity of $<0.045^{\circ} \mathrm{C}$; temperature range of $-20^{\circ} \mathrm{C}$ to $650^{\circ} \mathrm{C}$; resolution of 76,800 pixels $(320 \times 240)$ and frame rate of $60 \mathrm{~Hz}$. We calibrated the system before each scan by scanning a heated pad of known/controlled temperature, and the test was always performed between 9:00 am and 11:30 am to avoid daily temperature variations. Patients were comfortably seated $50 \mathrm{~cm}$ away from the camera. Patients were asked to blink normally for a few seconds and then to open 
their eyes as wide as possible as the scan was obtained. The process was repeated twice. The image acquisition was nearly instantaneous; thermal density was plotted on a color scale from deep blue to brown red, passing by cyan blue, green, yellow orange, and red, representing from low to high temperatures (Figure 1).

All images were stored on a portable storage device and then uploaded into a computer for further analysis. The images were analyzed with the FLIR Webviewer; a software provided by the digital thermal camera manufacturer (http:// www.flir.com/thermography/americas/us/view/?id=58384). A total of five points were measured on each cornea: central $1 \mathrm{~mm}$, temporal, nasal, superior, and inferior fields. We used the average of these five corneal temperature measurements to minimize any bias on the basis of conjunctival vascularity surrounding the cornea. Since normal ranges for forehead temperature (captured by digital thermal camera: range: $34.1{ }^{\circ} \mathrm{C}-37.2^{\circ} \mathrm{C}$ ) were previously published, we used forehead temperature as a control for erroneous measurements and excluded from the analysis any patients with a forehead temperature below $32.1^{\circ} \mathrm{C}$ and those with forehead temperature above $37.2^{\circ} \mathrm{C} .{ }^{21,22}$

\section{Statistical analysis}

Statistical analysis was made using an excel spreadsheet (Excel 2007; Microsoft Corporation, Redmond, WA, USA). A one-way analysis of variance test was used to identify the difference in the variability of the means among the groups regarding temperature and age and by using a $P$-value of less than 0.05 for statistical difference. A Tukey's least significance difference test was then performed to assess the statistical difference between means within the study groups. The mean ocular surface temperature (OST) was plotted against age for each group, and the correlation coefficient $(R)$ was calculated in order to determine if there was a linear dependency between the variables. Finally, the results of both phakic groups (ARC and clear lens) were summarized into a single group and the means compared against the pseudophakic group (PCIOL) using a two-sample $t$-test for means of two groups with different variances, using a $P$-value of less than 0.05 for statistical significance.

\section{Results}

We included 56 eyes, of which 28 had a diagnosis of ARC, 12 more had a clear lens status, and 16 eyes had PCIOL. The mean \pm standard deviation OST of the ARC group was $34.14^{\circ} \mathrm{C} \pm 1.51^{\circ} \mathrm{C}$; the group with clear lens had a mean OST of $34.43^{\circ} \mathrm{C} \pm 2.27^{\circ} \mathrm{C}$; and the group with PCIOL had a mean OST of $34.97^{\circ} \mathrm{C} \pm 1.57^{\circ} \mathrm{C}$. There were no statistical differences among the study groups regarding $\operatorname{OST}(P=0.3)$. After including all the phakic patients (disregarding their cataract status) into a single group, the mean OST was $34.44^{\circ} \mathrm{C} \pm 1.56^{\circ} \mathrm{C}$. There was no statistical difference against the pseudophakic (PCIOL) group $(P=0.2)$.

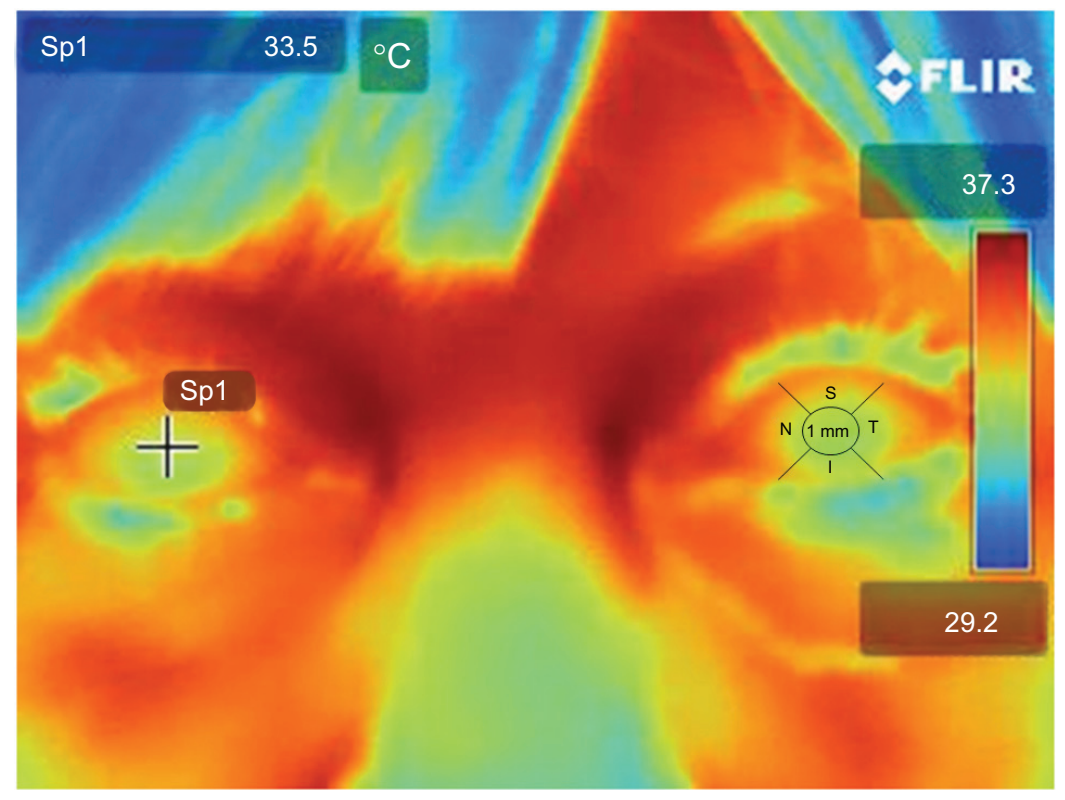

Figure I Digital thermal image from a representative patient.

Notes: The cursor is placed in the center and then moved around into five different positions of the corneal surface. The process is repeated twice per eye. The left eye depicts the five zones from where every measurement was taken.

Abbreviations: S, superior; I, inferior; N, nasal; T, temporal; I mm, central cornea I mm. 
Regarding the mean age of the groups, both ARC and PCIOL groups had very similar (and nonstatistically significantly different) mean ages $(63.75 \pm 11.15$ vs $64.38 \pm 3.79$ years of age). However, the group of patients with clear lens had a significant lower mean age (29.83 \pm 9.35 years of age), with $P<0.01$. After grouping all the phakic patients into a single group, the mean age (53.57 \pm 18.93 years of age) was still statistically lower than the pseudophakic group $(P<0.01)$.

Figure 2 summarizes the charts in which we plot the OST and the age of each group. Table 1 summarizes each group respective correlation coefficient and its significance level. In Chart A, the age was plotted against the mean OST of all patients with ARC, in which a weak, nonsignificant negative correlation was observed. The same type of behavior was observed in Chart B in which the OSTs of all the phakic patients were plotted against their age. Finally, the OST of the pseudophakic group had a very weak positive correlation with their ages, without statistical significance.

\section{Discussion}

Infrared detection, as a thermal imaging technique, was developed during the second half of the past century. ${ }^{1,23}$ Its medical applications have expanded rapidly as it is a simple noninvasive technique that provides real-time measurements and allows quick diagnosis with minimum equipment requirements. ${ }^{1,4,24}$ The available evidence about its use in medicine is large and covers a wide array of fields. ${ }^{1,16}$ In ophthalmology, changes in OST have been described in several pathological states as well as during and after surgical procedures. ${ }^{17,24,25}$ Although the relationship between OST and superficial factors like the tear film has been extensively described, ${ }^{12,26}$ the relationship with intraocular structures as well as with choroidal and retinal vasculature has remained somewhat inconclusive and has precluded its comprehensive use as a diagnostic tool of posterior pathology. While some studies have shown successfully that patients with decreased ocular circulation, like carotid artery stenosis, can experience a reduction in OST, ${ }^{16,27}$ the contrary has been more difficult to prove, with little information available and the existing studies showing conflicting results.

Despite the potential useful application of ocular thermal imaging as a diagnostic or prognostic tool, there are some variables that should be considered and controlled for during the test, because they can affect the OST readings. Tear film stability is one such variable; ${ }^{1,26}$ an unstable film
A

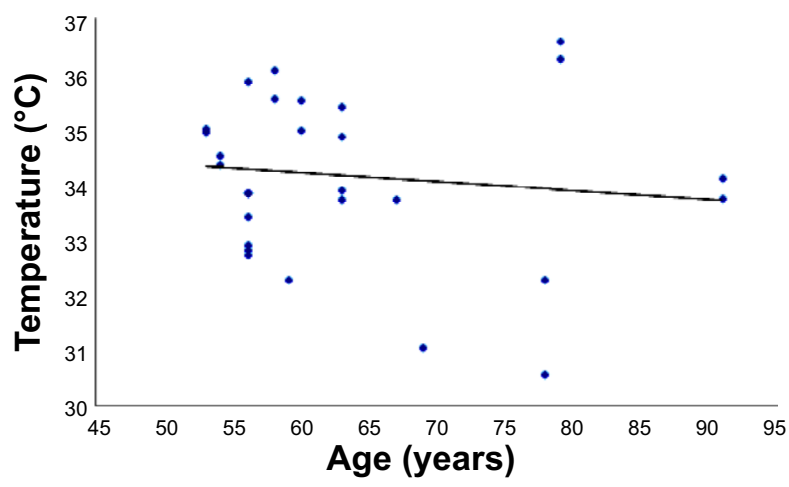

- Age vs Temp ${ }^{\circ}$ (clear) _ Lineal (age vs temp ${ }^{\circ}$ [clear])
B

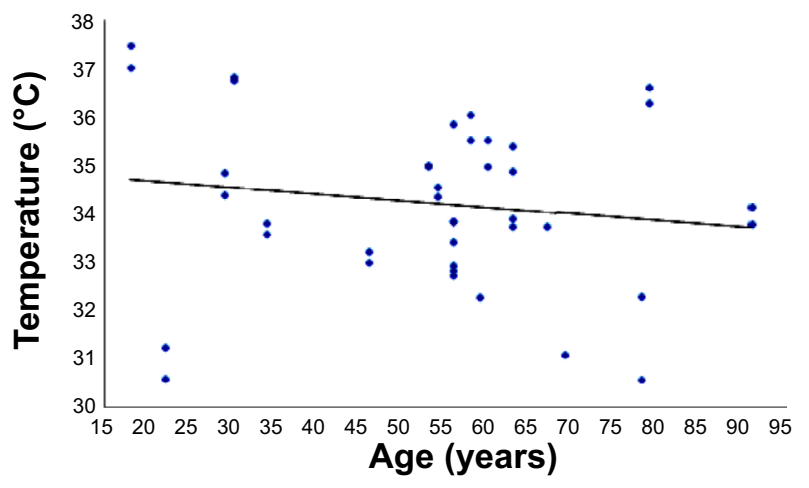

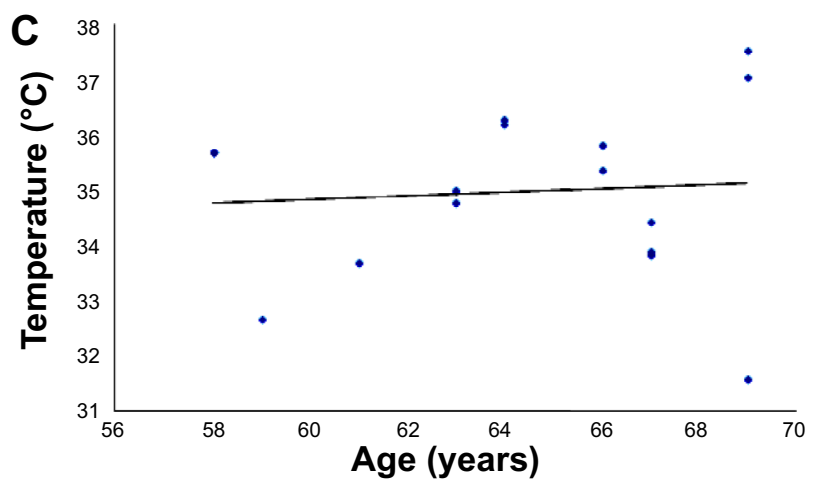

- Age vs temp ${ }^{\circ}(\mathrm{PCIOL})$ Lineal (age vs temp $\left.{ }^{\circ}[\mathrm{PCIOL}]\right)$

Figure 2 Graphic representation of the correlation between patient's age and ocular surface temperature. Abbreviations: Temp, temperature; PCIOL, posterior chamber intraocular lens. 
Table I Correlation coefficient

\begin{tabular}{lll}
\hline & $\boldsymbol{R}$ & $\boldsymbol{P}$ \\
\hline Age vs ARC OST & $-0.1 \mathrm{I}$ & 0.50 \\
Age vs phakic OST & -0.14 & 0.30 \\
Age vs pseudophakic OST & 0.08 & 0.70 \\
\hline
\end{tabular}

Abbreviations: ARC, age-related cataract; OST, ocular surface temperature.

due to deficient tear formation or disruption of the tear film secondary to the instillation of drops or defects on the blinking mechanism (anatomical defects or decreased rate), can increase the degree of local evaporation and yield lower readings. ${ }^{1,26}$ Conversely, OST tends to increase immediately after eyelid closure and can be up to $1.5^{\circ} \mathrm{C}$ warmer if prolonged more than 5 minutes. ${ }^{1,8}$ The way in which OST is assessed is also important to be considered; an average of various readings from different areas is more desirable than a single assessment. Studies in healthy eyes have shown that nasal areas of the eye tend to be warmer than their temporal counterparts and the limbus tends to be warmer than the corneal center by $0.45^{\circ} \mathrm{C}-1.0^{\circ} \mathrm{C} .{ }^{7,28,29}$ Therefore, OST variation within the cornea can be controlled by taking the average of several different points on the cornea. Environmental conditions are also important to consider, since variables like room temperature may have a positive correlation with OST of up to $0.15^{\circ} \mathrm{C}-0.2^{\circ} \mathrm{C}$ for each Celsius degree rise. ${ }^{1,30}$ Variations in air flow and room humidity can vary the local heat transfer; therefore, a period of room adaptation before measurement is advised..$^{30}$

Although the difference in OST among sexes, race and between left and right eye has been studied, there has been no evidence so far that supports the effect of these variables on OST. ${ }^{1}$ On the other hand, several studies have shown consistently that OST decreases with age, with a reduction of $0.01^{\circ} \mathrm{C}-0.023^{\circ} \mathrm{C}$ per year and it is more evident among middle-aged subjects and above..$^{28,31,32}$

In our current study, we actively controlled for the variables that have been reported to effect OST readings; furthermore, the average of several points of the corneal surface temperature was assessed at the same time in order to prevent any possible confounding outlier. Our results showed that the mean OSTs across all three groups were similar to those previously reported $\left(\approx 32.9^{\circ} \mathrm{C}-36^{\circ} \mathrm{C}\right)$ in the literature. Despite the fact that patients with clear lens were significantly younger than patients from the other groups $(P<0.01)$, the mean OST was not statistically different $(P=0.3)$. Comparison of age between phakic and pseudophakic groups was still lower in the pseudophakic group $(P<0.01)$, where the mean OST was similar between the groups. Despite the similar OST among the groups, older patients tended to have lower OST readings than younger patients in the clear lens and ARC groups (in concordance with previous studies). This trend continues and slightly increases after grouping both groups into a single phakic group. Interestingly, this trend seems to reverse in the pseudophakic group, in which older individuals appeared to have slightly higher OST readings. The lens has relatively low thermal conductivity, which might prevent the transference of heat from the posterior segment toward the ocular surface. Therefore, a slight increase in OST after cataract surgery seems to make sense. Conversely, if we assume that intraocular structures like the lens have no effect on OST as previously suggested, the trend of lower OST in older patients should have continued or even increased slightly. The pseudophakic group is where the decrease should have been more marked. Although the correlations are very weak and nonsignificant, there is a possibility that the small number of enrolled participants might have induced an error Type 2 .

Besides the relatively small number of participants in some of the groups, the present study has some limitations that we would like to address. Firstly, cataract was analyzed as a categorical variable as present or not present with no gradation and thus dichotomic instead of ordinal. A more precise control of the extent of cataract could be performed using the Lens Opacification Classification System III. The lens and corneal thickness may as well have a role on heat dissipation coming from intraocular structures. Therefore, careful assessment of these variables by means of optical coherent tomography should be done in further studies, in order to clarify their effect on OST.

Second, although most studies on OST (including this one), have shown a negative correlation between age and OST, most of the studies have included patients who were middle aged or above, where increased tear film problems are likely to increase. During the execution of our study, we tried to control for this type of confounder by excluding patients with dry eye diagnosis. Finally, although pseudophakia seems to have something to do with the change of age-OST trend, it is impossible to exclude the possibility that the trend is due to changes in the choroidal/retinal blood flow. This question could not be answered with the current study design.

In summary, digital thermography is a noninvasive, noncontact imaging procedure, which is capable of generating real-time assessments of OST. Although our results might suggest that cataract extraction and PCIOL implantation seem to induce a mild increase in OST, enough to at least neutralize the trend of lower OST among older patients, this effect 
was not clear and not statistically significant. More studies with greater samples are desirable in order to improve the optimization of the use of digital thermography as a helpful diagnostic/prognostic tool in clinical practice.

\section{Disclosure}

A preliminary version of this study has never been presented as a paper or poster or submitted for publication. The authors do not have financial or economic interest to disclose. There were no funds or grants allocated to this research project.

\section{References}

1. Purslow C, Wolffsohn JS. Ocular surface temperature: a review. Eye Contact Lens. 2005;31(3):117-123.

2. Mencucci R, Mazzotta C, Rossi F, et al. Riboflavin and ultraviolet. A collagen crosslinking: in vivo thermographic analysis of the corneal surface. J Cataract Refract Surg. 2007;33(6):1005-1008.

3. Harding JR. Investigating deep venous thrombosis with infrared imaging. IEEE Eng Med Biol Mag. 1998;17(4):43-46.

4. Shih SR, Li HY, Hsiao YL, Chang TC. The application of temperature measurement of the eyes by digital infrared thermal imaging as a prognostic factor of methylprednisolone pulse therapy for Graves' ophthalmopathy. Acta Ophthalmol. 2010;88(5):e154-e159.

5. Mapstone R. Measurement of corneal temperature. Exp Eye Res. 1968;7(2):237-243.

6. Wachtmeister L. Thermography in the diagnosis of diseases of the eye and the appraisal of therapeutic effects. A preliminary report. Acta Ophthalmol (Copenh). 1970;48(5):945-958.

7. Acharya UR, Ng EY, Yee GC, Hua TJ, Kagathi M. Analysis of normal human eye with different age groups using infrared images. J Med Syst. 2009;33(3):207-213.

8. Mapstone R. Determinants of corneal temperature. Br J Ophthalmol. 1968;52(10):729-741.

9. Martin DK, Fatt I. The presence of a contact lens induces a very small increase in the anterior corneal surface temperature. Acta Ophthalmol (Copenh). 1986;64(5):512-518.

10. Chang TC, Hsiao YL, Liao SL. Application of digital infrared thermal imaging in determining inflammatory state and follow-up effect of methylprednisolone pulse therapy in patients with Graves' ophthalmopathy. Graefes Arch Clin Exp Ophthalmol. 2008;246(1):45-49.

11. Ng EY, Fok SC, Peh YC, Ng FC, Sim LS. Computerized detection of breast cancer with artificial intelligence and thermograms. J Med Eng Technol. 2002;26(4):152-157.

12. Singh G, Bhinder HS. Comparison of noncontact infrared and remote sensor thermometry in normal and dry eye patients. Eur J Ophthalmol. 2005;15(6):668-673.

13. Jones BF. A reappraisal of the use of infrared thermal image analysis in medicine. IEEE Trans Med Imaging. 1998;17(6):1019-1027.
14. Ring EF. Progress in the measurement of human body temperature. IEEE Eng Med Biol Mag. 1998;17(4):19-24.

15. Gratt BM, Anbar M. Thermology and facial telethermography: Part II. Current and future clinical applications in dentistry. Dentomaxillofac Radiol. 1998;27(2):68-74.

16. Galassi F, Giambene B, Corvi A, Falaschi G. Evaluation of ocular surface temperature and retrobulbar haemodynamics by infrared thermography and colour Doppler imaging in patients with glaucoma. Br J Ophthalmol. 2007;91(7):878-881.

17. Sodi A, Giambene B, Falaschi G, et al. Ocular surface temperature in central retinal vein occlusion: preliminary data. Eur J Ophthalmol. 2007;17(5):755-759.

18. Auker CR, Parver LM, Doyle T, Carpenter DO. Choroidal blood flow. I. Ocular tissue temperature as a measure of flow. Arch Ophthalmol. 1982;100(8):1323-1326.

19. Behrens A, Doyle JJ, Stern L, et al; Dysfunctional Tear Syndrome Study Group. Dysfunctional tear syndrome: a Delphi approach to treatment recommendations. Cornea. 2006;25(8):900-907.

20. Management and therapy of dry eye disease: report of the Management and Therapy Subcommittee of the International Dry Eye WorkShop (2007). Ocul Surf. 2007;5(2):163-178.

21. Agrawal S, Joshi M, Christoforidis JB. Vitreous inflammation associated with intravitreal anti-VEGF pharmacotherapy. Mediators Inflamm. 2013;2013:943409.

22. Tan L, Cai ZQ, Lai NS. Accuracy and sensitivity of the dynamic ocular thermography and inter-subjects ocular surface temperature (OST) in Chinese young adults. Cont Lens Anterior Eye. 2009;32(2):78-83.

23. Holmberg A. [The temperature of the eye during the application of hot packs, and after milk injections]. Acta Ophthalmol (Copenh). 1952;30(4):348-364.

24. Klamann MK, Maier AK, Gonnermann J, Klein JP, Pleyer U. Measurement of dynamic ocular surface temperature in healthy subjects using a new thermography device. Curr Eye Res. 2012;37(8):678-683.

25. Galassi F, Giambene B, Corvi A, Falaschi G, Menchini U. Retrobulbar hemodynamics and corneal surface temperature in glaucoma surgery. Int Ophthalmol. 2008;28(6):399-405.

26. Zelichowska B, Rozycki R, Tlustochowicz M, Kujawa A, Kalicki B, Murawski P. [The usefulness of thermography in the diagnostics of dry eye syndrome]. Klin Oczna. 2005;107(7-9):483-487. Polish.

27. Morgan PB, Smyth JV, Tullo AB, Efron N. Ocular temperature in carotid artery stenosis. Optom Vis Sci. 1999;76(12):850-854.

28. Alio J, Padron M. Influence of age on the temperature of the anterior segment of the eye. Measurements by infrared thermometry. Ophthalmic Res. 1982;14(3):153-159.

29. Alio J, Padron M. Normal variations in the thermographic pattern of the orbito-ocular region. Diagn Imaging. 1982;51(2):93-98.

30. Freeman RD, Fatt I. Environmental influences on ocular temperature. Invest Ophthalmol. 1973;12(8):596-602.

31. Efron N, Young G, Brennan NA. Ocular surface temperature. Curr Eye Res. 1989;8(9):901-906.

32. Morgan PB, Soh MP, Efron N. Corneal surface temperature decreases with age. Cont Lens Anterior Eye. 1999;22(1):11-13.
Clinical Ophthalmology

\section{Publish your work in this journal}

Clinical Ophthalmology is an international, peer-reviewed journal covering all subspecialties within ophthalmology. Key topics include: Optometry; Visual science; Pharmacology and drug therapy in eye diseases; Basic Sciences; Primary and Secondary eye care; Patient Safety and Quality of Care Improvements. This journal is indexed on Submit your manuscript here: http://www.dovepress.com/clinical-ophthalmology-journal

\section{Dovepress}

PubMed Central and CAS, and is the official journal of The Society of Clinical Ophthalmology (SCO). The manuscript management system is completely online and includes a very quick and fair peer-review system, which is all easy to use. Visit http://www.dovepress.com/ testimonials.php to read real quotes from published authors. 